\title{
HUBUNGAN PELATIHAN KETERAMPILAN DENGAN PENGETAHUAN KADER TENTANG PERAN FUNGSI SISTEM 5 MEJA DI POSYANDU WILAYAH KERJA PUSKESMAS JATINANGOR KABUPATEN SUMEDANG TAHUN 2018
}

\author{
Fardila Elba ${ }^{1}$, Risma Ristiani ${ }^{2}$ \\ ${ }^{1,2}$ )Diploma IV Kebidanan Fakultas Kedokteran Universitas Padjadjaran \\ fardilaelba@yahoo.com
}

\begin{abstract}
ABSTRAK
Pos Pelayanan Terpadu atau Posyandu yaitu sarana yang memudahkan masyarakat dalam mendapatkan pelayanan kesehatan. Dalam penyelenggaraan posyandu yang memiliki peran penting salah satunya adalah kader. Kader memiliki peran dan fungsi dalam kegiatan Posyandu salah satunya yaitu menjadi pelaksana sistem 5 meja di Posyandu, namun pada kenyataannya sistem 5 meja belum berjalan secara optimal hal tersebut dapat dipengaruhi oleh beberapa faktor salah satunya pengetahuan. Tujuan dari penelitian ini yaitu untuk mengetahui hubungan frekuensi pelatihan yang di ikuti dengan pengetahuan kader tentang peran dan fungsinya di posyandu terutama pada sistem 5 meja. Metode : Penelitian ini adalah analitik dengan pendekatan crosssectional. Sampel dalam penelitian ini adalah kader di wilayah keja Puskesmas Jatinangor. Pengambilan sampel menggunakan Teknik Propotionate Stratified random samplingdengan jumlah sampel 83 responden. Analisis data menggunakan uji Gamma.

Penelitian menunjukan bawha terdapat hubungan yang signifikan antara frekuensi pelatihan dengan tingkat pengetahuan $(\mathrm{p}=0.000)$.

Terdapat hubungan antara frekuensi pelatihan yang pernah diikuti dengan pengetahuan kader tentang peran fungsi sistem 5 meja di Posyandu wilayah kerja Puskesmas jatinangor kabupaten Sumedang.
\end{abstract}

Kata Kunci: Kader, Posyandu, Sistem 5 meja

\begin{abstract}
Integrated Service Posts or Posyandu are facilities that make it easier for people to get health services. In the implementation of posyandu which has an important role, one of them is a cadre. Cadres have a role and function in Posyandu activities, one of which is to implement a 5-table system in Posyandu, but in the 5-table system it has not run optimally, this can be done by several factors, one of which is knowledge. The purpose of this study is to study the relationship of training that discusses knowledge about roles and functions at the posyandu which is devoted to the 5 table system.

This study is analytical using cross-sectional. The sample in this study was a cadre in the area of Jatinangor Health Center. Sampling using the Proposiate Stratified random sampling technique with a sample of 83 respondents. Data analysis using Gamma test.

The study showed a significant participation rate between training with knowledge level ( $p=$ 0,000 ).

Participating in training that had been attended by cadres' knowledge about the role of the 5-table system in the work area of the jatinangor health center in Sumedang district.

Keyword: Cadres, Posyandu, System 5 tables
\end{abstract}




\section{PENDAHULUAN}

Posyandu atau Pos Pelayanan Terpadu merupakan salah satu UKBM yang memudahkan masyarakat dalam mendapatkan pelayanan kesehatan. ${ }^{1}$ Kementerian Kesehatan menyebutkan terdapat 289.635 Posyandu di Indonesia pada tahun 2014. ${ }^{2}$ Data Riset kesehatan Dasar Tahun 2013 terdapat 49.193 Posyandu di Jawa Barat dan sebanyak 1.567 Posyandu terdapat di kabupaten Sumedang. Posyandu yang aktif sebanyak 770 dari seluruh Posyandu yang ada di kabupaten Sumedang. ${ }^{3}$ Pemanfaatan UKBM di Kecamatan Jatinangor didapatkan hanya sekitar $46 \%$ yang memanfaatkan posyandu untuk mendapatkan pelayanan kesehatan. Alasan mereka tidak memanfaatkannya adalah tidak perlu. ${ }^{5}$ Menurut data Riskesdas di Jawa Barat tahun 2013 masih ada yang memiliki status imunisasi tidak lengkap sebanyak $(35,1 \%)$ dan tidak imunisasi $(8,3 \%)$. Untuk Sumedang terdapat $(14,6 \%)$ yang tidak melakukan imunisasi lengkap. Persentase frekuensi penimbangan pada anak umur 6-23 bulan selama enam bulan terakhir di Jawa Barat $(15,1 \%)$ tidak melakukan imunisasi dan di Sumedang masih ada $(4,8 \%)$ yang tidak melakukan imunisasi. ${ }^{6}$ Penelitian yang dilakukan di Kabupaten Kuningan Jawa Barat tentang motivasi kader meningkatkan keberhasilan kegiatan Posyandu mengatakan pekerjaan juga menjadi faktor dimana responden dalam penelitian tersebut banyak dari Ibu rumah tangga sehingga mereka memiliki banyak waktu luang untuk melakukan kegiatan Posyandu. Penelitian tersebut juga mengatakan usia menjadi salah satu faktor kerena semakin bertambah usia seseorang semakin banyak menyerap informasi yang memengaruhinya, dimana usia produktif dapat memberikan pengaruh dan menjadi sumber informasi agar mengikuti seluruh kegiatan posyandu. ${ }^{9}$ Penelitian lain yang dilakukan di Puskesmas Palasari kabupaten Subang tahun 2014 tentang faktor-faktor yang berhubungan dengan keaktifan kader dalam kegiatan Posyandu menyatakan bahwa ibu yang bekerja ternyata lebih aktif dalam kegaiatan Posyandu. Penelitian tersebut tidak sejalan dengan teori yang menyatakan semakin banyak pekerjaan seseorang makan akan semakin sedikit bersosialisasi yang menyebabkan kesadaran dan tanggung jawabnya terhadap perannya sebagai kader menurun. ${ }^{10}$ Lamannya bekerja menjadi kader mempengaruhi pengetahuan kader dari hasil penelitian kader yang bekerja $>5$ tahun memiliki pengetahuan yang baik. Masa kerja yang lama dapat meningkatkan pengetahuan karena pengalaman ataupun mengikuti banyak pelatihan. Pengetahuan yang baik pada kader yang bekerja $>5$ tahun ternyata tidak menjamin kinerja yang baik dari penelitian yang sama dikatakan kinerja kader buruk hal ini bisa terjadi karena pelatihan yang diikuti tidak cukup banyak. ${ }^{9}$

Beberapa peneliti yang melakukan penelitian terhadap karakteristik kader tersebut salah satunya penelitian yang dilakukan di Puskesmas Talun Kabupaten 
Blitar tentang hubungan Motivasi dan Pendidikan kader dengan kinerja kader Posyandu, hasil penelitian tersebut mengatakan bahwa pendidikan menjadi salah satu faktor yang memengaruhi keaktifan kader karena semakin tinggi pendidikan seseorang makan ia akan semakin mudah dalam menerima informasi yang disampaikan sehingga kader dapat terlibat aktif dalam setiap kegiatan Posyandu.

Pada kegiatan posyandu terdapat beberapa penyelenggara yang memiliki peran penting salah satunya adalah kader. Kader merupakan bagian dari masyarakat itu sendiri yang sukarela bersedia, mampu, dan memiliki waktu untuk melaksanakan kegiatan Posyandu sehingga kader sangat mempengaruhi berjalannya kegiatan Posyandu itu sendiri.

Dalam lingkup kesehatan seseorang kader memiliki peran dalam lingkungan masyarakat. Kader memiliki kedudukan atau posisi sosial dalam masyarakat, sehingga muncul harapan dari masyarakat itu sendiri. Kader memiliki peran dalam menjalankan program pemerintah yaitu kegiatan posyandu, dimana kader sebagai kunci utama dalam pelaksanaan kegiatan posyandu. Peran kader dalam Posyandu dibagi menjadi 3 bagian, yaitu sebelum hari buka Posyandu (persiapan), saat hari buka Posyandu (pelaksanaan), dan setelah hari buka Posyandu (setelah pelaksanaan). ${ }^{18}$

Sebelum hari buka Posyandu, seorang kader mempunyai peran dalam melakukan persiapan dalam kegiatan Posyandu diantaranya; menyebarluaskan informasi mengenai hari buka Posyandu agar masyarakat mengetahui bahwa akan ada pelayanan kesehatan, dapat melalui pertemuan antar warga, pengumuman, atau memberi surat edaran; melakukan pembagian tugas antar kader yang mencakup pendaftaran, penimbangan, pencatatan, penyuluhan, pemberian makanan tambahan, dan pelayanan yang dapat dilakukan oleh kader; melakukan koordinasi dengan petugas kesehatan seperti bidan atau yang lainnya terkait dengan pelayanan yang akan diberikan saat Posyandu; menyiapkan peralatan dan perlengkapan yang akan dibutuhkan saat Posyandu; menyiapkan buku catatan kegiatan Posyandu. ${ }^{3} \quad$ Saat hari buka Posyandu, kader memiliki peran untuk menjalankan kegiatan posyandu dengan melakukan pendaftaran pada balita, ibu hamil, ibu nifas, ibu menyusui, dan sasaran lainnya; melakukan pelayanan kesehatan ibu dan anak yang dapat dilakukan oleh kader, seperti penimbangan, pengukuran tinggi badan, pengukuran lingkar kepala anak, pemantauan aktifitas anak, pemantauan imunisasi anak, pemantauan terhadap tindakan orangtua tentang pola asuh yang dilakukan pada anak, pemantauan tentang permasalahan anak balita, dan lainnya; membimbing orangtua dalam melakukan pencatatan hasil pengukuran dan pemantauan kondisi anak balita; melakukan penyuluhan mengenai pola asuh pada anak balita.; memotivasi orangtua balita untuk melakukan pola asuh yang baik pada anaknya; 
memberikan penghargaan pada orangtua yang telah hadir ke Posyandu dan meminta mereka untuk senantiasa terus datang setiap kali ada kegiatan Posyandu sampai anaknya berusia lima tahun; memberikan informasi pada orangtua untuk menghubungi kader jika terjadi permasalahan terkait anak balitanya; melakukan pencatatan kegiatan yang telah dilakukan selama kegiatan Posyandu berlangsung. ${ }^{3}$ Setelah hari buka Posyandu, kader akan melakukan kunjungan rumah pada anak balita yang tidak hadir saat hari buka Posyandu, anak yang kurang gizi, atau anak yang mengalami gizi buruk rawat jalan, dan lain-lain; memotivasi masyarakat mengenai Perilaku Hidup Bersih dan Sehat (PHBS); melakukan pertemuan dengan tokoh masyarakat dan pimpinan wilayah terkait untuk menyampaikan informasi mengenai hasil Posyandu dan meminta dukungan untuk keberlangsungan kegiatan Posyandu; melakukan pertemuan dengan masyarakat untuk berdiskusi mengenai kegiatan Posyandu. Hasil diskusi masyarakat akan digunakan untuk rencana tindak lanjut pada kegiatan Posyandu; mempelajari Sistem Informasi Posyandu (SIP). SIP adalah sistem pencatatan data atau informasi mengenai pelayanan yang diselenggarakan di Posyandu.

Adapun beberapa karakteristik kader yang memengaruhi peran dan fungsi kader di Posyandu yaitu umur, tingkat pendidikan, tingkat pengetahuan, pelatihan kader, jarak dari rumah ke Posyandu, dukungan suami atau keluarga, status pernikahan, pekerjaan, lamanya menjadi kader, dan penghasilan. ${ }^{4}$ Selain hal tersebut frekuensi pelatihan yang diikuti kader ternyata juga dapat menjadi faktor yang mempengaruhi pengetahuan kader. Penelitian yang dilakukan oleh Tri Sunarsih di Desa Banyurejo Sleman. Yogyakarta pada tahun 2012 mengatakan bahwa sistem 5 meja di posyandu belum semuanya berjalan secara optimal sejalan dengan penelitian bahwa pada pelayanan Meja 1 sampai Meja $3(100 \%)$ melakukan kegiatan dengan kategori baik sedangkan pada Meja 4 (26.7\%) yang melakukan kegiatan sehingga secara keseluruhan Meja 4 dikategorikan tidak baik. ${ }^{5}$ Penelitian ini sejalan dengan penelitian yang dilakukan oleh Suryani di Puskesmas Silih Nara Kabupaten Aceh Tengah tahun 2012, menemukan bahwa dalam pelaksanaannya penyuluhan sewajarnya dilakukan setiap selesai dilakukan penimbangan, namun pada kenyataannya banyak petugas atau kader tidak melakukannya. ${ }^{6}$ Sistem yang digunakan dalam pelaksanaan posyandu adalah sistem lima meja yang meliputi Meja I melayani pendaftaran dan pencatatan bayi, balita, ibu hamil, ibu menyusui, dan pasangan usia subur. Meja II melayani penimbangan berat badan. Meja III melayani pengisian KMS (Kartu Menuju Sehat) berdasarkan hasil penimbangan berat badan. Meja IV melayani informasi berat badan bayi atau balita naik atau tidak, ibu hamil dengan risiko tinggi, pasangan usia subur yang belum menjadi akseptor KB, penyuluhan kesehatan, dan pelayanan pemberian makanan tambahan, 
oralit, vitamin A, tablet zat besi, kondom, pil KB untuk kunjungan ulang. Meja V melayani pemberian imunisasi, pemeriksaan kehamilan, pemeriksaan kesehatan dan pengobatan, dan pelayanan KB IUD atau suntik. ${ }^{15}$ Dalam Penelitian yang dilakukan oleh Tri Sunarsih pada Meja 5 pun hanya (33.3\%) yang melakukan kegiatan sehingga secara keseluruhan Meja 5 dikategorikan tidak baik. $^{4}$ Mengingat pentingnya pelaksanaan sistem 5 meja di posyandu peneliti tertarik untuk mengetahui adakah hubungan frekuensi pelatihan yang kader ikuti dengan pengetahuan yang kader miliki tentang sistem 5 meja di Posyandu wilayah kerja Puskesmas Jatinangor Kabupaten Sumedang.

\section{METODE PENELITIAN}

Jenis penelitiani yang digunakan adalah analitik dengan rancangan penelitian crosssectional. Sumber data yang digunakan adalah data primer yang diperoleh dari hasil kuisoner. ${ }^{6}$ Populasi dalam penelitain ini adalah semua kader di posyandu wilayah kerja Puskesmas Jatinangor kabupaten Sumedang sebanyak 83 kader. Sampel diambil dengan cara Propotionate Stratified random sampling.

\section{HASIL DAN PEMBAHASAN}

Tabel 1 Distribusi Frekuensi Pengetahuan

\begin{tabular}{lcc}
\hline $\begin{array}{c}\text { Pengetahuan } \\
\text { Responden }\end{array}$ & $\begin{array}{c}\text { Frekuensi } \\
(\mathbf{F})\end{array}$ & $\begin{array}{c}\text { Persentase } \\
(\boldsymbol{\%})\end{array}$ \\
\hline 1. Baik & 60 & 72,3 \\
2.Cukup & 17 & 20.5 \\
3.Kurang & 6 & 7.2 \\
\hline \multicolumn{1}{c}{ Total } & 83 & 100 \\
\hline
\end{tabular}

Berdasarkan tabel 1 dalam penelitian ini didapatkan 60 responden $(72.3 \%)$ memiliki pengetahuan baik, 17 responden memiliki pengetahuan cukup (20.5\%), dan 6 responden memiliki pengetahuan kurang (7.2\%).

Tabel 2 Distribusi Frekuensi Pelatihan

\begin{tabular}{|c|c|c|}
\hline $\begin{array}{l}\text { Pelatiha } \\
\text { n }\end{array}$ & $\begin{array}{l}\text { Frekuens } \\
\quad \text { i ( F ) }\end{array}$ & $\begin{array}{c}\text { Persentas } \\
\text { e }(\%)\end{array}$ \\
\hline 1. Sering & 1 & 1,3 \\
\hline 2. Cukup & 42 & 50.6 \\
\hline 3. Kurang & 40 & 48.1 \\
\hline Total & 83 & 100 \\
\hline
\end{tabular}

Berdasarkan penelitian pada tabel 2 Terdapat 42 responden $(50.6 \%)$ memiliki frekuensi pelatihan cukup yaitu pelatihan yang di ikuti sebanyak 3-5 kali, 40 responden $(48.1 \%)$ masuk ke dalam kategori dengan frekuensi pelatihan kurang yaitu $<2$ kali, dan frekuensi pelatihan sering sebanyak $(1,3 \%)$ dengan frekuensi > 5 kali

Tabel 3 Hubungan frekuensi pelatihan dengan pengetahuan

\begin{tabular}{|c|c|c|c|c|c|c|c|c|c|}
\hline \multirow{3}{*}{$\begin{array}{l}\text { Frekuensi } \\
\text { Pengetahuan }\end{array}$} & \multicolumn{6}{|c|}{ Pengetahhuan } & \multirow{3}{*}{ Total } & \multirow{3}{*}{$\%$} & \multirow{3}{*}{$\begin{array}{l}* * \mathrm{p}- \\
\text { Value }\end{array}$} \\
\hline & \multicolumn{2}{|c|}{ Baik } & \multicolumn{2}{|c|}{ Cukup } & \multicolumn{2}{|c|}{ Kurang } & & & \\
\hline & $\mathrm{N}$ & $\%$ & $\mathrm{~N}$ & $\%$ & $\mathrm{~N}$ & $\%$ & & & \\
\hline Sering & 1 & 100 & 0 & 0 & 0 & 0 & 1 & 100 & \\
\hline Cukup & 37 & 88.1 & 5 & 11,9 & 0 & 0 & 42 & 100 & 0.000 \\
\hline Kurang & 22 & 55 & 12 & 30 & 6 & 15 & 40 & 100 & \\
\hline
\end{tabular}


Berdasarkan tabel 3 dapat diketahui bahwa sebanyak 60 orang memiliki pengetahuan baik tentang system 5 meja, 37 orang diantaranya (\%) kader dengan frekuensi pelatihan dalam kategori cukup dan dengan frekuensi pelatihan kategori sering sebanyak (\%). Ha dalam penelitian ini adalah adanya hubungan yang signifikan antara frekuensi pelatihan dengan pengetahuan kader tentang sistem 5 meja. Untuk mengetahui hubungan dilakukan uji gamma didapatkan nilai koefisien gamma sebesar 3.872, ini berarti terdapat hubungan yang positif antara lama menjadi kader dengan pengetahuan dan hubungan yang ada relatif kecil, yaitu $73.5 \%$. Nilai signifikansi dapat dilihat pada kolom pvalue didapat nilai signifikansi sebesar 0.000 . Karena nilai signifikansi lebih kecil dari taraf signifikansi yang digunakan 0.05 $(0.000<0.05)$, maka tolak Ho dan simpulkan terdapat hubungan yang signfikan antara frekuensi pelatihan dengan pengetahuan pada taraf signfikansi $5 \%$. Berdasarkan penelitian sebanyak 17 orang memiliki pengetahuan cukup tentang sistem 5 meja, 5 orang dengan frekuensi pelatihan dalam kategori cukup, dan 12 orang diantaranya (\%) dengan frekuensi pelatihan dalam kategori kurang dan Respon dengan pengetahuan kurang sebanyak 6 responden dengan frekuensi pelatihan kategori kurang 6 orang. Pelatihan adalah sesuatu proses pendidikan jangka pendek dengan menggunakan prosedur yang sistematis dan terorganisir, sehingga karyawan operasional belajar pengetahuan teknik pengerjaan dan keahlian untuk tujuan tertentu. pelatihan sebagai usaha sistematis untuk menguasai keterampilan, peraturan, konsep, ataupun cara berperilaku yang berdampak pada peningkatan kinerja, maka dapat ditarik kesimpulan bahwa pelatihan merupakan suatu bentuk bantuan dalam proses pembelajaran yang terorganisir dan sistematis dengan jangka waktu yang relatif singkat untuk meningkatkan pengetahuan dan keterampilan peserta pelatihan yang sifatnya praktis guna mencapai tujuan tertentu. Tujuan pelatihan tersebut jelas mengungkapkan bahwa pelatihan haruslah menjadi sarana pemenuh kebutuhan peserta pelatihan untuk dapat mengembangkan keterampilan, pengetahuan, sikap yang dapat dimanfaatkan oleh peserta pelatihan setelah mengikuti pelatihan tersebut sesuai dengan kompetensinya sebagai upaya pengembangan diri.

Beberapa faktor yang mempengaruhi Efektivitas pelatihan itu sendiri yaitu Materi atau isi pelatihan, Metode pelatihan, Pelatih (instruktur/trainer), peserta pelatihan, sarana pelatihan, evaluasi pelatihan. berdasarkan penelitian ini Terdapat hubungan antara frekuensi pelatihan dengan tingkat pengetahuan yang dimiliki oleh kader dimana semakin sering penelitian yang kader ikuti semakin baik pula pengetahuan yang dimiliki dan begitu pula sebaliknya semakin sedikit kader mengikuti 
pelatihan semakin kurang pula pengetahuan yang dimiliki. Dalam penelitian ini Pengetahuan yang baik di dukung dengan frekuensi pelatihan yang sering atau cukup hal tersebut masuk kedalam faktor peserta pelatihan dengan motivasi dan rasa ingin tahu yang tinggi sehingga berpengaruh terhadap pengetahuan yang dimiliki, sedangkan untuk kader dengan pengetahuan kurang ini dapat dilihat dari faktor peserta yang kurang antusias dalam mengikuti pelatihan atau bahkan lamanya menjabat menjadi kader masih dalam waktu yang singkat. Materi yang didapatkan juga bisa menjadi faktor yang mempengaruhi dalam penelitian ini dimana penelitian ini melihat tingkat pengetahuan tentang sistem 5 meja, mungkin saja responden belum pernah mengikuti pelatihan tentang sisitem 5 meja itu sendiri, seingga pengetahuan tentang materi tersebut masih kurang.

Peningkatan pengetahuan dapat dilakukan dengan berbagai cara, salah satunya kegiatan pelatihan. Peingkatan pengetahuan setelah diberikan pengetahuan bisa terjadi bila materi yang disampaikan mudah dimengerti oleh kader. Pelatihan kader dalam kegiatan posyandu dapat juga meningkatkan keterampilan kader. Salah satunya keterampilan dalam melaksanakan system 5 meja di posyandu. Keterampilan adalah hasil dari latihan berulang, yang dapat disebut perubahan yang meningkat atau progresif oleh orang yang mempelajari keterampilan tersebut. Keterampilan kader posyandu merupakan salah satu kunci keberhasilan dalam system pelayanan di posyandu, karena dengan pelayanan kader yang terampil akan membuat respon positif dari masyarakat yang mendorong masyarakat untuk datang ke posyandu.

Pengetahuan merupakan hasil penginderaan terhadap suatu objek melalui panca indera manusia yakni penglihatan, pendengaran, penciuman rasa, dan raba dengan sendiri yang menghasilkan "tahu". Pengetahuan dipengaruhi oleh beberapa faktor salah satunya pendidikan, semakin tinggi pendidikan seseorang diharapkan akan semakin luas pula pengetahuan yang dimiliki.

Pengetahuan memengaruhi sikap seseorang, semakin banyak aspek positif yang diketahui makan akan menimbulkan sikap positif terhadap objek. Perilaku akan lebih langgeng bila didasari pengetahuan. Pengetahuan yang cukup memiliki 6 tingkat yaitu Tahu, memahami, aplikasi, analisis, sintesis, dan evaluasi. Pengetahuan yang cukup memiliki 6 tingkat yaitu Tahu, memahami, aplikasi, analisis, sintesis, dan evaluasi. Tahu yaitu seseorang dapat menyebutkan, menguraikan, mengidentifikasi, dan menyatakan. Memahami yaitu dapat menjelaskan dan menginterpretasinya secara benar. Aplikasi yaitu seseorang dapat menggunakan pengetahuan atau materi yang telah di pelajari pada situasi dan kondisi sebenarnya. 
Analisis merupakan kemampuan menyatakan materi kedalam komponen-komponen yang masih ada kaitannya satu sama lain. Sintesis sendiri memiliki arti dimana seseorang dapat menghubungkan bagian-bagian di dalam suatu keseluruhan yang baru. Evaluasi yaitu seseorang sudah bisa melakukan penilaian terhadap suatu objek atau materi. ${ }^{3}$ Faktor yang memengaruhi pengetahuan dibagi menjadi faktor internal dan eksternal. Faktor internal terdiri dari Pendidikan, Pekerjaan, Umur, sedangkan untuk faktor eksternal meliputi lingkungan dan sosial budaya. Pendidikan merupakan bimbingan yang diberikan seseorag untuk perkembangan orang lain. Pada umumnya semakin tinggi pendidikan seseorang maka akan semakin mudah dalam menerima informasi.

\section{SIMPULAN}

Berdasarakan penelitiani ini pengetahuan baik 60 responden $(72.3 \%)$, pengetahuan cukup 17 responden (20.5\%), dan pengetahuan kurang 6 responden $(7.2 \%)$. Pada penelitian ini frekuensi pelatihan sering sebanyak 1 responden, frekuensi cukup 37 responden, dan frekuensi kurang 22 responden. Kesimpulan dari penelitian ini terdapat hubungan antara frekuensi pelatihan yang pernah diikuti dengan pengetahua kader tentang peran fungsi sistem 5 meja di Posyandu wilayah kerja Puskesmas jatinangor kabupaten Sumedang. Pelatihan kader ini sangat penting dilakukan untuk meningkatkan pengetahuan kader sehingga meningkat kualitas posyandu termasuk dalam pelaksanaan sistem 5 meja, dengan meningkatnya kualitas poyandu dapat meningkatkan kunjungan masyarakat ke posyandu.

\section{REFERENSI}

1. Kemenkes RI. Petunjuk Teknis Penyelenggaraan Posyandu Remaja. Jakarta:Kementerian Kesehatan RI. 2018

2. Kemenkes RI. Profil kesehatan indonesia 2014 . Jakarta: Kementerian Kesehatan RI. 2015

3. Hidayat TS, Jahari, AB. Perilaku Pemanfaatan Posyandu HubungannyaDengan Status Gizi Dan Morbjditas Balitabul. Penelit. Kesehat. 2012;40(1):1-10

4. Sunarsih, Tri. Evaluasi Program 5 Meja pada Posyandu balita di Desa Banyurejo Sleman. Yogyakarta: 2012

5. Suryani. Gambaran kegiatan posyandu dan status gizi balita di wilayah kerja Puskesmas Silih Nara Kabupaten Aceh Tengah tahun 2012; 2012.

6. Dahlan S. Langkah-Langkah Membuat Proposal Penelitian Bidang Kedokteran dan Kesehatan. Jakarta: Sagung Seto; 2008

7. Budiman, Rianto A. Kapita Selekta Kuesioner Pengetahuan dan Sikap dalam Penelitian Kesehatan. Jakarta: Salemba Medika; 2013.

8. Azizah Nur Rohim SZ, Yuli Kusumawati. Perbedaan Pengetahuan Pada Remaja Putri Setelah Diberi PendidikanDengan Metode

9. Ceramah Tanpa Media Dan Ceramah Dengan Media Buku Cerita. Jurnal Kesehatan.2016;1

10. Legi, Nonce L.Faktor yang berhubungan dengan keaktifan kader posyandu di wilayah kerja puskesmas ranotana weru.Volume 7 No. 2 November; 2015 
11. Djuahaeni, H., S. Gondodiputro, dan R. Suparman. Motivasi Kader Meningkatkan Keberhasilan Kegiatan Posyandu di Kabupaten Kuningan Jawa Barat. MKB, vol. 42, no. 4, hh.140-14; 2010

12. Putra, Gede Tamblang Baswara. Gambaran pengetahuan dan kinerja kader Posyandu di wilayah kerja upt Puskesmas Mengwi kabupaten Badung . E-JURNAL MEDIKA, VOL. 5 NO.10, OKTOBER, 2016

13. Sodarsono. Hubungan Motivasi dan Pendidikan Kader Dengan Kinerja kader Posyandu di Wilayah Kerja Puskesmas Talun kabupaten Blitar; 2010

14. Suhat. Faktor-faktor yang berhubungan dengan keaktifan kader dalam kegiatan Posyandu (studi di Puskesmas Palasari kabupaten Subang ). Jurnal Kesehatan Masyarakat. 2014 Juli; 10 (1): 73 - 79

15. Budiman, Agus Riyanto. Kapita Selekta Kuesioner. Jakarta Selatan;2013
16. Azizah Nur Rohim SZ, Yuli Kusumawati. Perbedaan Pengetahuan Pada Remaja Putri Setelah Diberi Pendidikan Dengan Metode Ceramah Tanpa Media Dan Ceramah Dengan Media Buku Cerita. Jurnal Kesehatan.2016;1

17. ŞEŞEN E. Role Theory and Its Usefulness in Public Relations European Journal of Business and Social Sciences. 2015; Vol. 4 No. 01:136 - 43.

18. Resa Rahayu NY, Amrin Farzan. Peran Kader Posyandu Dalam UpayaPeningkatan Pemanfaatan Posyandu Di Wilayah Kerja Puskesmas Mokoau Tahun 2017. Jurnal Ilmiah Mahasiswa Kesehatan Masyarakat. 2017; Vol 2 No 6.

19. Wawan A, Dewi M. Teori dan Pengukuran Pengetahuan, Sikap, dan Perilaku Manusia. Yogyakarta : Nuha Medika. 2010

20. Azizah Nur Rohim SZ, Yuli Kusumawati. Perbedaan Pengetahuan Pada Remaja Putri Setelah Diberi PendidikanDengan Metode Ceramah Tanpa Media Dan Ceramah Dengan Media Buku Cerita. Jurnal Kesehatan.2016;1

21. Budiman, Agus Riyanto. Kapita Selekta Kuesioner. Jakarta Selatan; 2013 